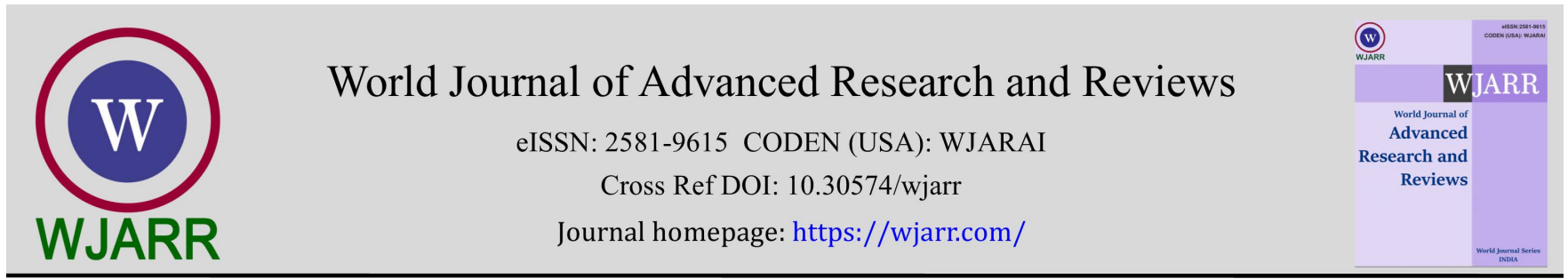

(RESEARCH ARTiCle)

Check for updates

\title{
The role of posters and interactive quizzes through social media on community understanding of mental health and immunity during Covid-19 pandemic
}

\author{
Ramadhani Rizki Zamzam 1, Muhammad Faris Zharfan 1, Indratama Budiwicaksono ${ }^{1}$ and Maftuchah \\ Rochmanti 2,* \\ ${ }^{1}$ Medical Program, Faculty of Medicine, Universitas Airlangga, Surabaya, Indonesia. \\ 2 Department of Anatomy, Histology, and Pharmacology, Faculty of Medicine, Universitas Airlangga, Surabaya, Indonesia.
}

World Journal of Advanced Research and Reviews, 2022, 13(01), 369-378

Publication history: Received on 06 December 2021; revised on 09 January 2022; accepted on 11 January 2022

Article DOI: https://doi.org/10.30574/wjarr.2022.13.1.0025

\begin{abstract}
Introduction: The COVID-19 pandemic has had many negative impacts on the entire world's population. Research has proven that people who have experienced a pandemic will have a tendency to experience mental health disorders. In addition to anxiety, individuals tend to lose direction regarding optimal dietary patterns and nutritional status. Medical staff and social media are the most widely used sources of information to find information about COVID-19 by the public. Therefore, the public needs to receive the right and correct information. This study aims to illustrate the public's understanding of mental health and immune enhancement during the COVID-19 pandemic. Methods: Ten Instagram accounts have been used to upload educational posters as well as conduct evaluations using quizzes on Instagram stories. The population in this study were Instagram users. Results: The quiz received a total of 1,689 answers, including 1,432 correct answers, and 266 incorrect answers. Conclusion: Most people have understood the material presented through educational posters.
\end{abstract}

Keywords: Mental Health; Immunity; Quiz; Poster; COVID-19

\section{Introduction}

Coronavirus (COVID-19), is a highly contagious virus that was first observed in the city of Wuhan, China in December 2019. It is now an emergency for the world's public health. There are already $160,813,869$ confirmed cases of COVID19 in the world that have been notified by WHO as of May 14, 2021[1]. Indonesia is the fourth highest population in the world, and lastly on June 4 2021, Indonesia had reported 1,837,126 cases and 51,095 deaths [2].

The condition of the COVID-19 pandemic, which is on a global scale, not only causes fear of infection itself, the pandemic can also have a negative impact on people's mental health. COVID-19 has spread anxiety throughout the world's population, and efforts to prevent it have had an impact on mental health due to isolation, as well as economic barriers experienced by individuals. Research has proven that people who have experienced a pandemic will have a tendency to experience psychological stress, sleep disorders, anxiety, and post-traumatic stress disorder (PTSD) [3-5]. Burdened with uncertainty, the public tends to seek positive solutions to maintain their own mental health [6,7]. The American Psychiatry Association (APA) reports that 48\% of Americans are anxious about the possibility of contracting COVID-19 [8]. A study in China also showed that $53.8 \%$ of respondents reported moderate to severe mental disorders [9] while in Denmark also shows that mental health rates during the COVID-19 period are decreased compared to previous years [10]. Moreover, some public groups are also given a greater impact than others. During the COVID-19 pandemic, women

\footnotetext{
${ }^{*}$ Corresponding author: Maftuchah Rochmanti

Department of Anatomy, Histology, and Pharmacology, Faculty of Medicine, Universitas Airlangga, Surabaya, Indonesia. 
tend to have greater stress levels than men, moreover, individuals with a younger age tend to have higher stress levels than those who are older [11].

In an effort to reduce the spread of the virus, strict national level regulations have been established by various, including regulations for people to reduce social gatherings and to stay at home. Especially in times of self-confinement, individuals tend to lose direction regarding optimal dietary patterns and adequate nutritional status to maintain their respective fitness [12]. To avoid infection, a healthy and excellent immune system is very important, and this can be achieved by individuals by establishing a balanced and adequate diet every day $[13,14]$. Physical activity appears to be declining due to government restrictions on COVID-19. The decrease in physical activity may be offset by the psychological effects of the pandemic. Maintaining physical activity can inhibit the impact of the pandemics on mental health. It found that physical activity decreased in all corners of the world [15]. One study also investigated changes in physical activity, sitting time, and screen time due to public restrictions on COVID-19 and its link to mental health. There was a large decrease in physical activity and an increase in sedentary time in the population, especially in the physically active population prior to COVID-19. There was also a link between decreased physical activity and increased screen time and the increasing negative impact of mental health due to this. Recent data also show that individuals who previously rarely did physical activity had a 32\% increased risk of hospital admission due to COVID-19, which shows how important it is to maintain or increase physical activity time during the pandemic [16]. Physical activity has a strong association with reduced anxiety and depressive symptoms [17-19]. The combination of an adequate and nutritious diet and regular physical activity carried out by individuals can reduce the negative effects of COVID-19, both in terms of direct transmission to the psychological effects that can be experienced due to self-isolation caused by COVID-19 indirectly [20].

Aside from mental health as well as nutrition and physical activity issues during the pandemic, there are also issues of public knowledge on COVID-19 topics as well. Due to the uncertainty of this novel virus, there are some things that are not understood about the COVID-19 virus itself, in terms of its prevention and also the impacts it can cause to the society. This is a challenge thanks to the amount of incorrect information on social media that can obscure public's understanding about COVID-19 [21]. The level of public knowledge and attitudes towards COVID-19 has an important role in preventing and overcoming the negative impacts that this virus can cause, either directly or indirectly. People's levels of knowledge and attitudes can be heavily affected by varying degrees of panic and emotions which can be made more uncertain by the continuous spread of the virus [22]. Therefore, it is very important for the public to receive the right and correct information. One easy way and can be done by many parties is to use social media platforms to increase public knowledge.

According to research [23], the most widely used source of information about COVID-19 is direct information from doctors (62.9\%), followed by social media (53.7\%). Based on his research, more than half of Jordan (56.8\%) and Iraq (53.2\%) participants had sufficient levels of knowledge about COVID-19. The results of this study showed that medical staff and social media are the most widely used facilities to find information about COVID-19. Social media is an important source of information because of the level of spread and ease of access to it for all public circles. However, because COVID-19 is a new virus and is rapidly spreading around the world, there is a lot of information that can be accessed via the internet and media, although not all information conveyed is correct [24].

\section{Material and methods}

In the midst of technological advances, there are many easy ways that can be done by everyone to spread information to others. Various platforms have been provided to support this, especially in the midst of the still high COVID-19 pandemic conditions where many people are looking for information to get through this pandemic situation. Instagram is one of the social media that is widely used today because it can spread information in the form of photos or videos with the Coronavirus (COVID-19), is a highly contagious virus that was first observed in the city of Wuhan, China in December 2019. It is now an emergency for the world's public health. There are already $160,813,869$ confirmed cases of COVID-19 in the world that have been notified by WHO as of May 14, 2021[1]. Indonesia is the fourth highest population in the world, and lastly on June 4 2021, Indonesia had reported 1,837,126 cases and 51,095 deaths [2].

The condition of the COVID-19 pandemic, which is on a global scale, not only causes fear of infection itself, the pandemic can also have a negative impact on people's mental health. COVID-19 has spread anxiety throughout the world's population, and efforts to prevent it have had an impact on mental health due to isolation, as well as economic barriers experienced by individuals. Research has proven that people who have experienced a pandemic will have a tendency to experience psychological stress, sleep disorders, anxiety, and post-traumatic stress disorder (PTSD) [3-5]. Burdened with uncertainty, the public tends to seek positive solutions to maintain their own mental health [6,7]. The American Psychiatry Association (APA) reports that 48\% of Americans are anxious about the possibility of contracting COVID-19 
[8]. A study in China also showed that 53.8\% of respondents reported moderate to severe mental disorders [9] while in Denmark also shows that mental health rates during the COVID-19 period are decreased compared to previous years [10]. Moreover, some public groups are also given a greater impact than others. During the COVID-19 pandemic, women tend to have greater stress levels than men, moreover, individuals with a younger age tend to have higher stress levels than those who are older [11].

In an effort to reduce the spread of the virus, strict national level regulations have been established by various, including regulations for people to reduce social gatherings and to stay at home. Especially in times of self-confinement, individuals tend to lose direction regarding optimal dietary patterns and adequate nutritional status to maintain their respective fitness [12]. To avoid infection, a healthy and excellent immune system is very important, and this can be achieved by individuals by establishing a balanced and ad equate diet every day [13,14]. Physical activity appears to be declining due to government restrictions on COVID-19. The decrease in physical activity may be offset by the psychological effects of the pandemic. Maintaining physical activity can inhibit the impact of the pandemics on mental health. It found that physical activity decreased in all corners of the world [15]. One study also investigated changes in physical activity, sitting time, and screen time due to public restrictions on COVID-19 and its link to mental health. There was a large decrease in physical activity and an increase in sedentary time in the population, especially in the physically active population prior to COVID-19. There was also a link between decreased physical activity and increased screen time and the increasing negative impact of mental health due to this. Recent data also show that individuals who previously rarely did physical activity had a 32\% increased risk of hospital admission due to COVID-19, which shows how important it is to maintain or increase physical activity time during the pandemic [16]. Physical activity has a strong association with reduced anxiety and depressive symptoms [17-19]. The combination of an adequate and nutritious diet and regular physical activity carried out by individuals can reduce the negative effects of COVID-19, both in terms of direct transmission to the psychological effects that can be experienced due to self-isolation caused by COVID-19 indirectly [20].

Aside from mental health as well as nutrition and physical activity issues during the pandemic, there are also issues of public knowledge on COVID-19 topics as well. Due to the uncertainty of this novel virus, there are some things that are not understood about the COVID-19 virus itself, in terms of its prevention and also the impacts it can cause to the society. This is a challenge thanks to the amount of incorrect information on social media that can obscure public's understanding about COVID-19 [21]. The level of public knowledge and attitudes towards COVID-19 has an important role in preventing and overcoming the negative impacts that this virus can cause, either directly or indirectly. People's levels of knowledge and attitudes can be heavily affected by varying degrees of panic and emotions which can be made more uncertain by the continuous spread of the virus [22]. Therefore, it is very important for the public to receive the right and correct information. One easy way tand can be done by many parties is to use social media platforms to increase public knowledge.

According to research [23], the most widely used source of information about COVID-19 is direct information from doctors (62.9\%), followed by social media (53.7\%). Based on his research, more than half of Jordan (56.8\%) and Iraq (53.2\%) participants had sufficient levels of knowledge about COVID-19. The results of this study showed that medical staff and social media are the most widely used facilities to find information about COVID-19. Social media is an important source of information because of the level of spread and ease of access to it for all public circles. However, because COVID-19 is a new virus and is rapidly spreading around the world, there is a lot of information that can be accessed via the internet and media, although not all information conveyed is correct [24].addition of other features and access that is easy for many people to use. Therefore, we carry out this online research activity using the social media Instagram. We provide education to the public about the importance of mental health and good body immunity, especially in the midst of the COVID-19 pandemic conditions in the form of poster publications. This educational poster is expected to increase the knowledge of readers from all circles of Instagram social media users about the impact of the COVID-19 pandemic on mental health and immunity and provide a way to overcome both problems.

We use ten Instagram accounts with the number of followers of each account ranging from 350 - 1100 followers. Our education method is done by uploading posters that we have created in the Instagram feed and stories simultaneously, namely on July $12^{\text {th }}, 2021$ for a mental health educational poster titled "Diary of The Pandemic: Membangun Resiliensi di Tengah Krisis COVID-19 (Building Resilience in the Midst of the COVID-19 Crisis)" and on July 20 ${ }^{\text {th }}, 2021$ for an immune educational poster with the title "Stop Sedentary, Life Active and Healthy!". The material for our educational posters is taken from reliable literature that we then create in such a way so it can be easily understood by the public.

After uploading educational posters, we conducted an evaluation to find out how the public's knowledge pictured. We re-uploaded the quiz questions by using the quiz feature in the Instagram story section. The number of questions for each topic is 5 questions for mental health topics and 5 questions for immune topics. Our quiz questions were uploaded 
simultaneously on July $18^{\text {th }}, 2021$ for mental health topics and on July $21^{\text {th }}, 2021$ for immune topics. Then we monitored the results for 24 hours. We also provide a discussion for each quiz question for each topic the day after each quiz from each topic is uploaded.

From the quizzes we uploaded by each account, we got results that for mental health topics there were 1,370 viewers story posters, 190 likes on the poster feed, 4,142 viewers story quiz with a total of 885 people, and 3,876 viewers story discussion. As for immune topics, we got the results of 1,268 viewers of poster stories, 160 likes on the poster feed, 3,882 viewers of quiz stories with a total of 804 people, and 3,324 viewers of discussion stories. Furthermore, the results of our quiz are presented in the form of diagrams, tables, and graphs.

\section{Results and discussion}

The first educational poster titled "Diary of the Pandemic: Membangun Resiliensi di Tengah Pandemi COVID-19 (Building Resilience in the Midst of the COVID-19 Pandemic)", received a total of 190 likes on the feed and 1,370 views on Instagram stories. The interactive quiz received a total of 4,142 views and 885 answers on Instagram stories. 0 the 885 answers obtained, there were 813 correct answers and 72 incorrect answers with details on each question as follows (Figure 1).

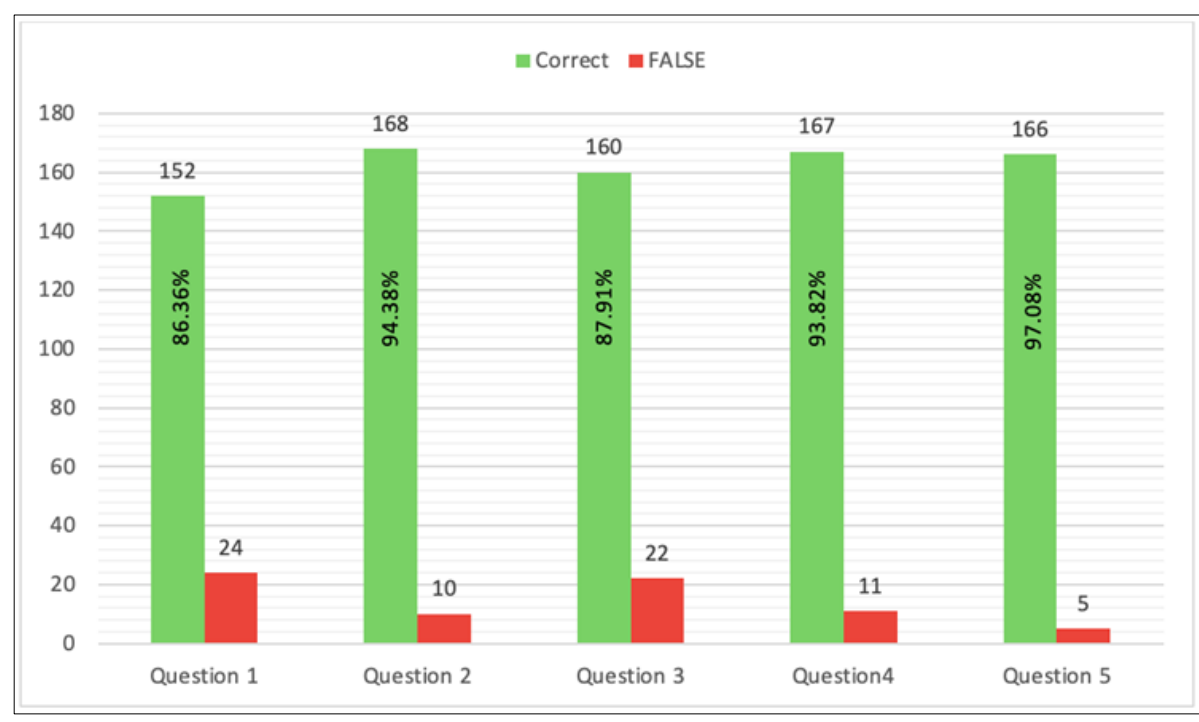

Figure 1 Interactive quiz answers distribution of "Diary of The Pandemic: Membangun Resiliensi di Tengah Pandemi COVID-19 (Building Resilience amid the COVID-19 Pandemic)"

Table 1 First poster interactive quiz questions

\begin{tabular}{|l|l|}
\hline Educational Poster Title & Quiz Questions \\
\hline $\begin{array}{l}\text { Diary of the Pandemic: } \\
\text { Membangun Resiliensi di } \\
\text { Tengah Pandemi COVID-19 } \\
\text { (Building Resilience Amid }\end{array}$ & $\begin{array}{l}\text { Loss of interest \& excitement, having sleep disturbances, feeling useless, reduced } \\
\text { concentration, energy and self-esteem are characteristics of... }\end{array}$ \\
\cline { 2 - 2 } the COVID-19 Pandemic) & The following are treatments for mental health problems, except... \\
\cline { 2 - 3 } & Mental illness cannot be cured. Myths/facts? \\
\cline { 2 - 2 } & Children can have mental illnesses, such as depression and anxiety. Myths/facts? \\
\cline { 2 - 2 } & $\begin{array}{l}\text { People with mental health disorders cannot socialize and must be isolated. } \\
\text { Myths/facts? }\end{array}$ \\
\hline
\end{tabular}

Based on table 1, the results obtained indicate that the interactive quiz questions regarding the characteristics of a mental health disorder contained 152 correct answers out of a total of 176 answers. Questions regarding treatment for mental health problems got 168 correct answers out of a total of 176 answers. For the myth and fact questions, 160 correct answers were obtained from a total of 182 answers regarding healing mental illness, 167 correct answers from 
a total of 178 answers regarding mental illness in children, and 166 correct answers from a total of 171 answers regarding the social aspects of people with mental health illness. Overall the percentage of answering questions correctly is $91.86 \%$.

For the first poster interactive quiz titled "Diary of The Pandemic: Membangun Resiliensi di Tengah Pandemi COVID-19 (Building Resilience in the Midst of the COVID-19 Pandemic)", the question most answered correctly was question number 5 regarding the social aspect of people with mental health illness with a percentage of correct answers of 97.08\%. This happens because as the times are growing, people are starting to open their minds and think that people with mental disorders should be helped, accompanied, and not shunned, as evidenced by the development of independent organizations that focus on caring for People with Mental Disorders (Orang Dengan Gangguan Jiwa or ODGJ). In the quiz question about one of the characteristics of mental health disorders, the percentage of correct answers obtained was the lowest percentage compared to other questions, which was $86.36 \%$. This is because ordinary people still underestimate the symptoms that may lead to a mental health disorder. Generally people are more likely to worry and seek help if the disease attacks the body physically, but has not realized the importance of mental health. Not many people are interested in the science of mental health disorders, even though there is a lot of information that can be accessed about mental health disorders so that many people can know more about the differences between each mental disorders.

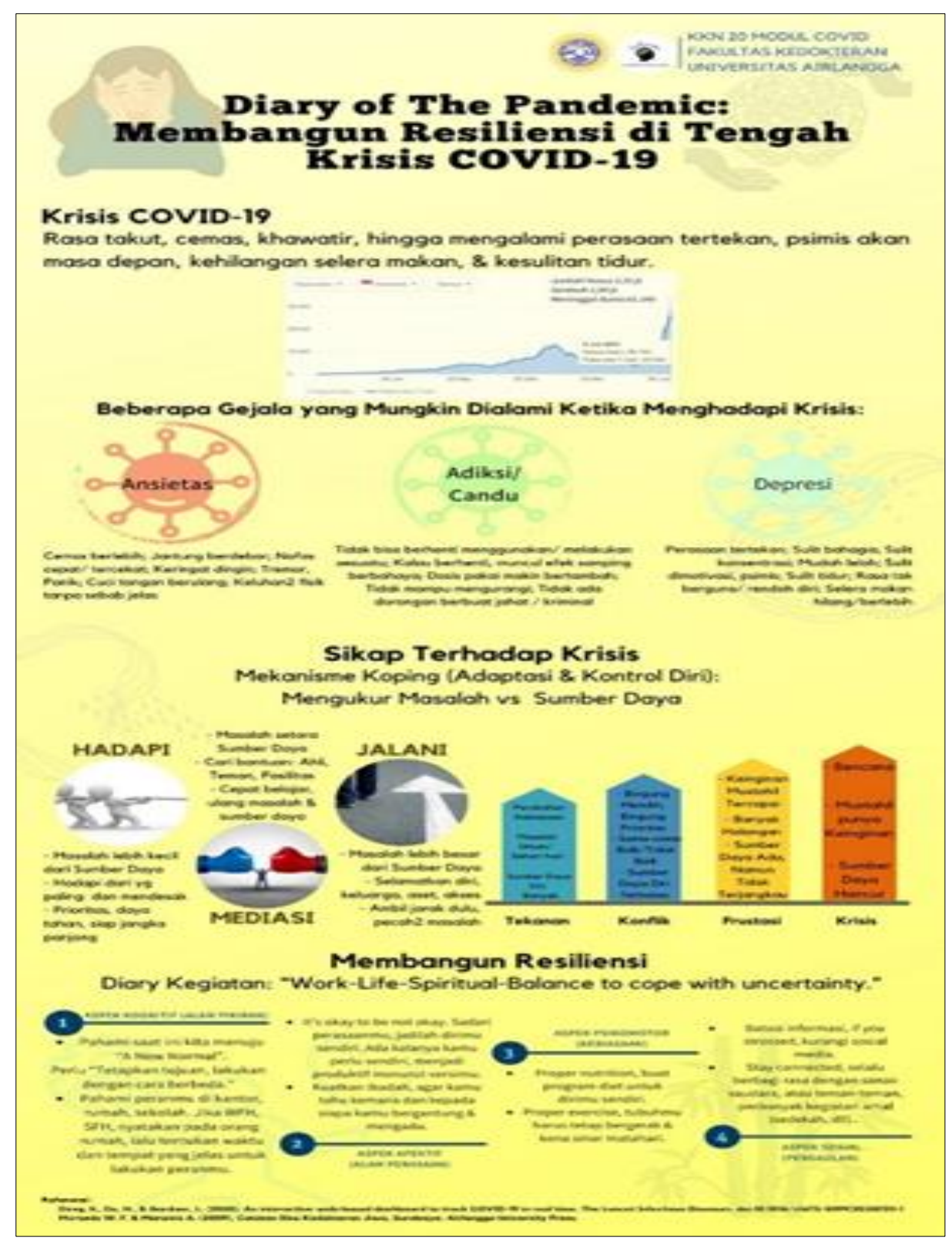

Figure 2 Educational poster of the first title 


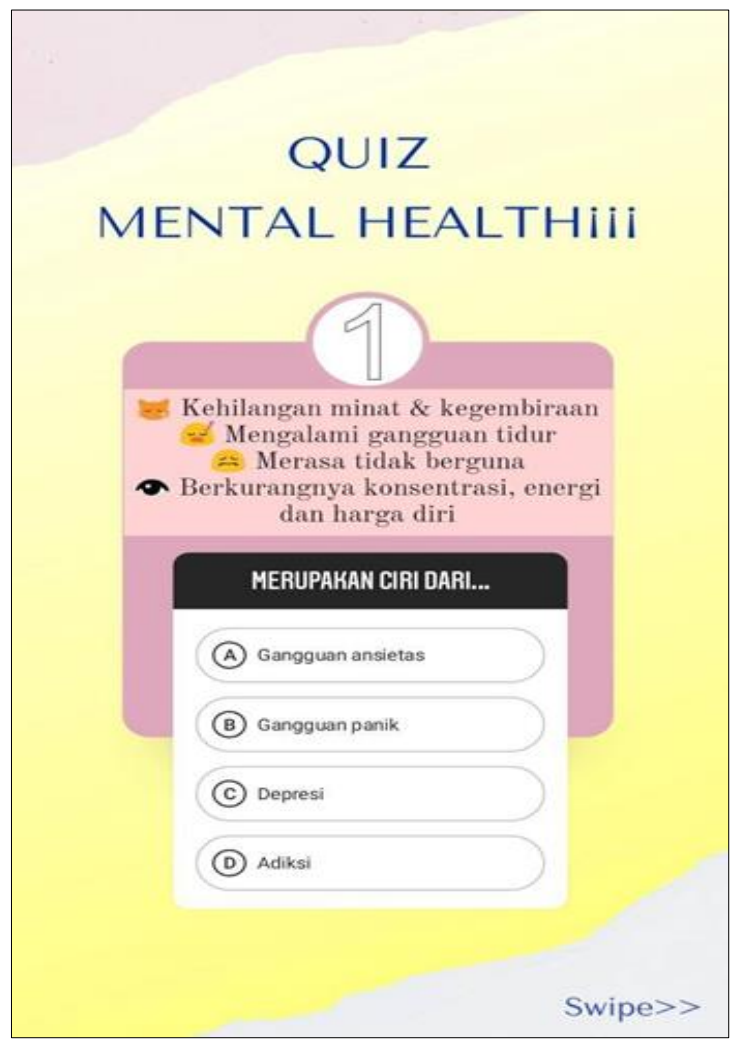

Figure 3 Interactive quiz of the first poster

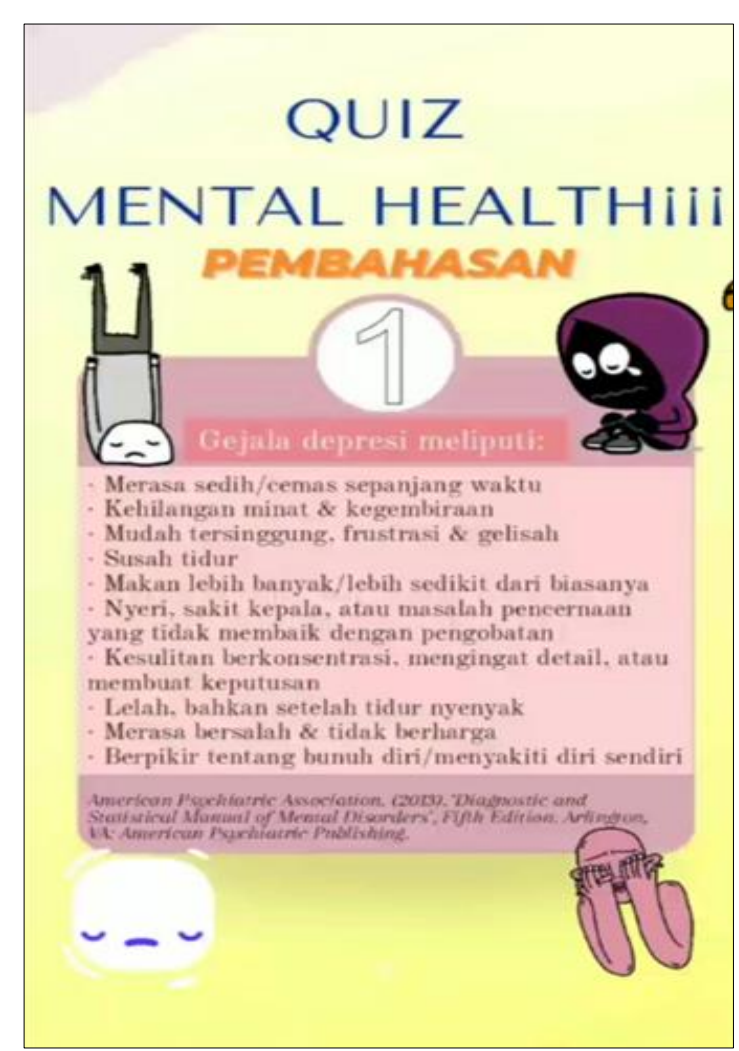

Figure 4 Interactive quiz discussion of the first poster

The second educational poster titled "Stop Sedentary, Live Active and Healthy!" received a total of 160 likes on the feed and 1,268 views on Instagram stories. The interactive quiz received a total of 3,882 views and 804 answers on Instagram stories. Of the 804 answers obtained, there were 610 correct answers and 194 incorrect answers with details on each question as follows.

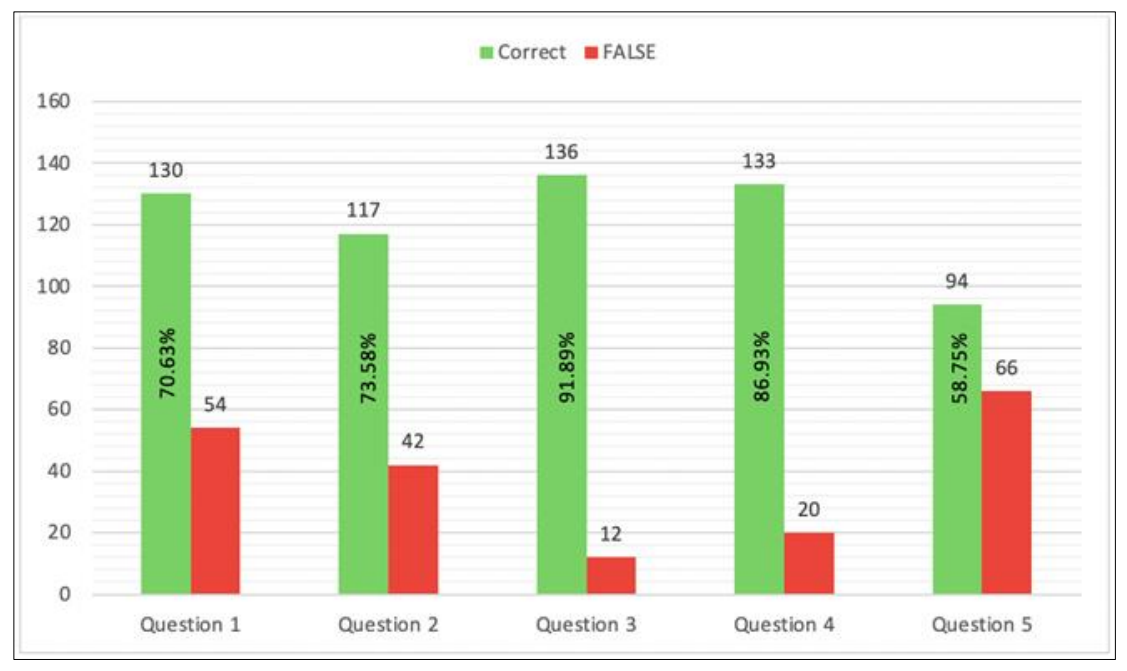

Figure 5 Interactive quiz answers distribution of "Stop Sedentary, Live Active and Healthy!"

Based on table 2, the interactive quiz questions for myth and fact, 130 correct answers were obtained from a total of 184 answers regarding the effect of sleep deprivation on the immune system, 117 correct answers from a total of 159 answers regarding supplement consumption, 136 correct answers from a total of 148 answers regarding the effects sedentary lifestyle, and 133 correct answers out of a total of 153 answers on how to increase immunity. On the question about the source of vitamin $C$, there were 94 correct answers out of a total of 160 answers. Overall the percentage of answering questions correctly is $75.87 \%$. 
Table 2 Second poster interactive quiz questions

\begin{tabular}{|l|l|}
\hline Educational Poster Title & Quiz Questions \\
\hline $\begin{array}{l}\text { Stop Sedentary, Live Active } \\
\text { and Healthy! }\end{array}$ & Lack of sleep has no effect on our immune system. Myths/facts? \\
\cline { 2 - 3 } & $\begin{array}{l}\text { Eating large amounts of food or supplements can help prevent or treat the } \\
\text { coronavirus. Myths/facts? }\end{array}$ \\
\cline { 2 - 2 } & $\begin{array}{l}\text { Sedentary lifestyle (lack of movement) cannot make the body susceptible to } \\
\text { infectious diseases because it has enough rest time. Myths/facts? }\end{array}$ \\
\cline { 2 - 2 } & Food and vitamins are not the only way to boost immunity. Myths/facts? \\
\cline { 2 - 2 } & $\begin{array}{l}\text { Vitamin C plays a role in supporting the immune system in our body and also as an } \\
\text { anti-oxidant. Which includes a high source of vitamin C is.... }\end{array}$ \\
\hline
\end{tabular}

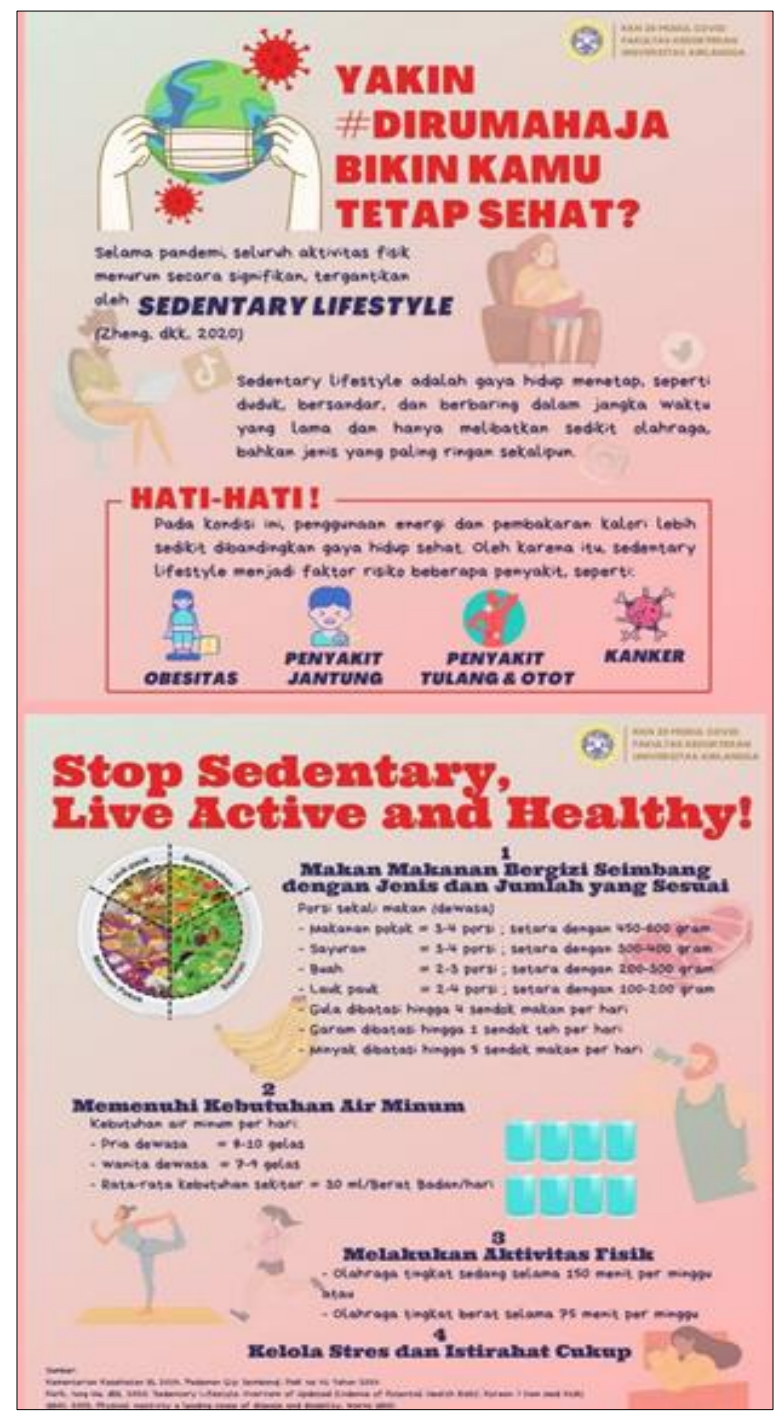

Figure 6 Educational poster of the second title

In the interactive quiz of educational poster with the topic of immune health, myth or fact questions about the effects of sedentary lifestyle are the question that gets the most correct answers with a correct percentage of $91.89 \%$. This is possible because it is common for ordinary people to think about healthy living habits that involve physical exercise routines, maintaining diet, and body immunity. The habit of sedentary and eating unhealthy foods has also been realized by many people that it is not a good thing. Sedentary lifestyle is known based on various studies related to various 
diseases such as heart and blood vessel disease, diabetes mellitus, cancer, obesity, and bone and muscle diseases [25]. The lowest percentage of correct answers of the five questions is in question number 5, which is about the source of vitamin C. Many respondents who answered the high source of vitamin C is oranges, even though the correct answer is in addition to oranges, broccoli and strawberries are also high sources of vitamin $\mathrm{C}$. This happens because during this time the thought of vitamin $\mathrm{C}$ has always been synonymous with citrus fruits. In fact, vitamin $\mathrm{C}$ is found in many fruits other than oranges and vegetables. In addition to citrus fruits, other fruits are very rich sources of vitamin $\mathrm{C}$, among others; melon, watermelon, berries, pineapple, strawberry, cherry, kiwi, mango, and tomato. Vitamin C from vegetables can be found in cabbage, broccoli, Brussels sprouts, bean sprouts, cauliflower, mustard, bell peppers, peas, and potatoes [26].

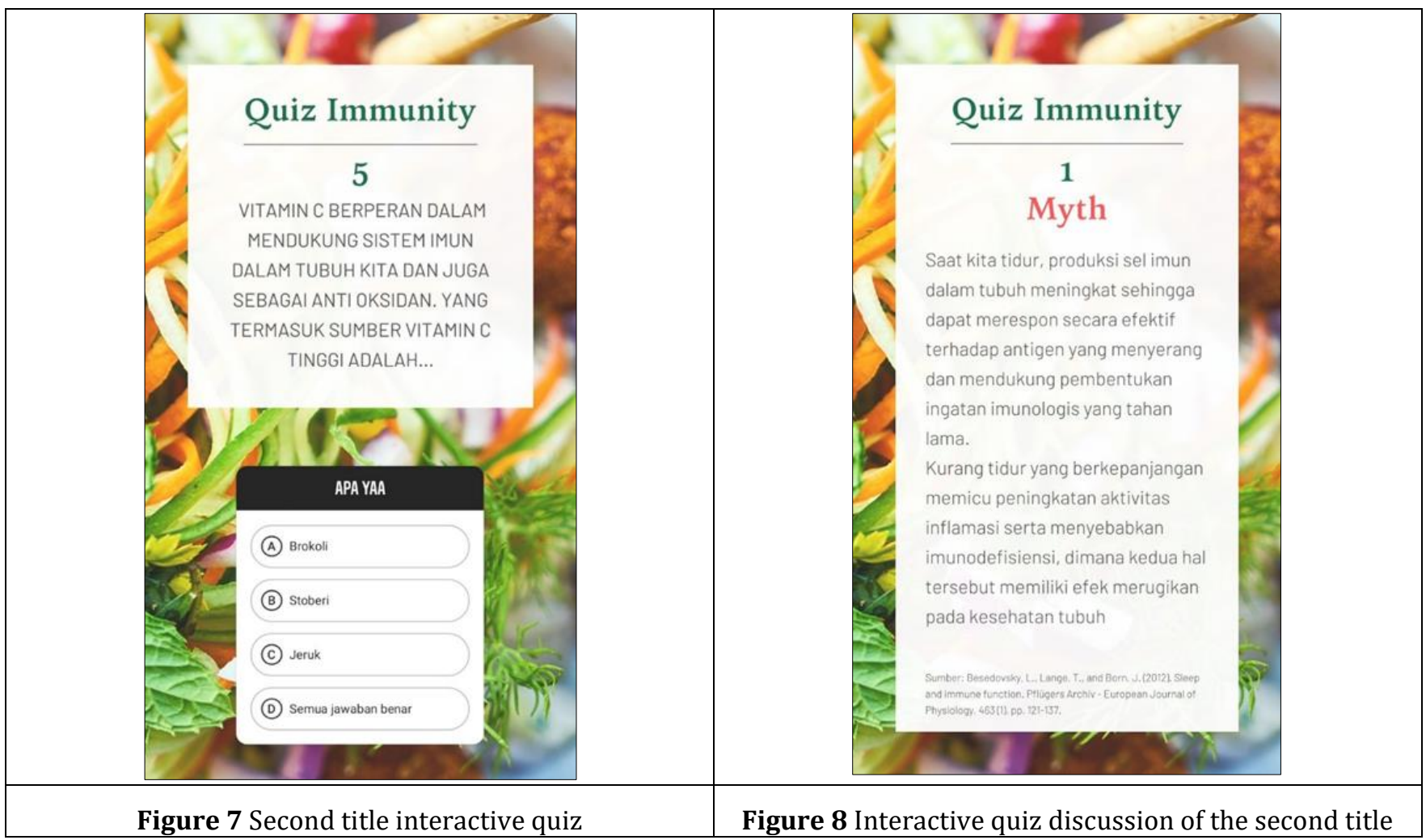

Based on the evaluation results of uploads of both educational posters and interactive quizzes, the number of response answers to quizzes is much less than the number of views. This may be due to the lack of public enthusiasm. However, the results of the answers obtained from interactive quizzes showed more responses that answered correctly for both the first title and the second title. This indicates that most of the public already understand the material presented through educational posters.

Social media is the most widely used source of information to find information about COVID-19 and most important because of the level of spread and ease of access to it for all public [24]. Therefore, the information provided to the public must certainly be true and easily understood by all social media users. In an effort to ensure the public is properly informed, discussions and answers from quizzes are also provided through Instagram Stories. The results were 3,876 views for the first title and 3,324 views for the second title from 10 Instagram accounts that each uploaded 5 stories.

\section{Conclusion}

Through the activities of giving educational posters, it can be seen that most of the public already understand the material delivered through educational posters. This is evidenced by the results of answers obtained from interactive quizzes showing more responses that answered correctly both for the first title and the second title.

This research activity still has some limitations, including the coverage of respondents who are only limited to followers of 10 Instagram accounts, and also the absence of measurement of the public knowledge level before being given educational posters, so it has not been able to assess the increase in public knowledge on the given topic. For the next 
similar research activity, it is expected to correct the shortcomings in this activity, so that the data and results obtained are more optimal and statistically tested.

\section{Compliance with ethical standards}

\section{Acknowledgments}

The authors would like to thank Faculty of Medicine, Universitas Airlangga for supporting this study.

\section{Disclosure of conflict of interest}

The authors declare that there is no conflict of interest that would affect the findings of this study.

\section{References}

[1] WHO. WHO Coronavirus (COVID-19) Dashboard [Internet]. covid19.who.int. 2021.

[2] Mahendradhata Y, Luh N, Eka P, Hasri ET. The Capacity of the Indonesian Healthcare System to Respond to. 9 July 2021; 1 -9.

[3] Ho CS, Chee CY, Ho RC. Mental Health Strategies to Combat the Psychological Impact of COVID-19 beyond Paranoia and Panic. Annals of the Academy of Medicine, Singapore. 2020; 49(1): 1-3.

[4] Lu W, Wang H, Lin Y, Li L. Psychological status of medical workforce during the COVID-19 pandemic: A crosssectional study. Psychiatry Research. April 2020; 288: 1-5.

[5] Fessell D, Cherniss C. Coronavirus Disease 2019 (COVID-19) and Beyond: Micropractices for Burnout Prevention and Emotional Wellness. Journal of the American College of Radiology. 2020; 17(6): 746-8.

[6] Cole CL, Waterman S, Hunter ECM, Bell V, Greenberg N, Rubin GJ, et al. Effectiveness of small group cognitive behavioural therapy for anxiety and depression in Ebola treatment centre staff in Sierra Leone. International Review of Psychiatry. 2021; 33(1-2): 189-97.

[7] Li S, Wang Y, Xue J, Zhao N, Zhu T. The impact of covid-19 epidemic declaration on psychological consequences: A study on active weibo users. Int J Environ Res Public Health [Internet] 2020 [accessed 13 April 2021]; 30(3): 201-205. International Journal of Environmental Research and Public Health. 2020; 17(6).

[8] Canady VA. APA poll finds nearly half anxious about getting COVID-19. Mental Health Weekly. 2020; 30(13): 55.

[9] Cuiyan W, Riyu P, Xiaoyang W, Yilin T, Linkang X, Cyrus SH, et al. Immediate Psychological Responses and Associated Factors during the Initial Stage of the 2019 Coronavirus Disease (COVID-19) Epidemic among the General Population in China. International Journal of Environmental Research and Public Health. 2020; 17(5): 125.

[10] Sønderskov KM, Dinesen PT, Santini ZI, Østergaard SD. The depressive state of Denmark during the COVID-19 pandemic. Acta Neuropsychiatrica. 2020; 2.

[11] Qiu J, Shen B, Zhao M, Wang Z, Xie B, Xu Y. A nationwide survey of psychological distress among Chinese people in the COVID-19 epidemic: Implications and policy recommendations. General Psychiatry. 2020; 33(2): 1-4.

[12] Iddir M, Brito A, Dingeo G, Del Campo SSF, Samouda H, La Frano MR, et al. Strengthening the immune system and reducing inflammation and oxidative stress through diet and nutrition: Considerations during the covid-19 crisis. Nutrients. 2020; 12(6): 1-39.

[13] Chacko SA, Song Y, Nathan L, Tinker L, De Boer IH, Tylavsky F, et al. Relations of dietary magnesium intake to biomarkers of inflammation and endothelial dysfunction in an ethnically diverse cohort of postmenopausal women. Diabetes Care. 2010; 33(2): 304-10.

[14] George SM, Neuhouser ML, Mayne ST, Irwin ML, Albanes D, Gail MH, et al. Postdiagnosis diet quality is inversely related to a biomarker of inflammation among breast cancer survivors. Cancer Epidemiology Biomarkers and Prevention. 2010; 19(9): 2220-8.

[15] Staff F. The Impact of Coronavirus on Global Activity [Internet]. blog.fitbit.com. 2020. 
[16] Hamer M, Kivimäki M, Gale CR, Batty GD. Since January 2020 Elsevier has created a COVID-19 resource centre with free information in English and Mandarin on the novel coronavirus COVID- 19. The COVID-19 resource centre is hosted on Elsevier Connect, the company's public news and information. January 2020.

[17] Raglin JS. Exercise and Mental Health: Beneficial and Detrimental Effects. Sports Medicine. 1990; 9(6): 323-9.

[18] Gordon BR, McDowell CP, Hallgren M, Meyer JD, Lyons M, Herring M Association of efficacy of resistance exercise training with depressive symptoms meta-analysis and meta-regression: Analysis of randomized clinical trials. JAMA Psychiatry. 2018; 75(6): 566-76.

[19] Ashdown-Franks G, Firth J, Carney R, Carvalho AF, Hallgren M, Koyanagi A, et al. Exercise as Medicine for Mental and Substance Use Disorders: A Meta-review of the Benefits for Neuropsychiatric and Cognitive Outcomes. Sports Medicine [Internet]. 2020; 50(1): 151-70.

[20] Meyer J, McDowell C, Lansing J, Brower C, Smith L, Tully M, et al. Changes in physical activity and sedentary behavior in response to covid-19 and their associations with mental health in 3052 as adults. International Journal of Environmental Research and Public Health. 2020; 17(18): 1-13.

[21] Azlan AA, Hamzah MR, Sern TJ, Ayub SH, Mohamad E. Public knowledge, attitudes and practices towards COVID19: A cross-sectional study in Malaysia. PLoS ONE. 2020; 15(5): 1-15.

[22] Zhong BL, Luo W, Li HM, Zhang QQ, Liu XG, Li WT, et al. Knowledge, attitudes, and practices towards COVID-19 among chinese residents during the rapid rise period of the COVID-19 outbreak: A quick online cross-sectional survey. International Journal of Biological Sciences. 2020; 16(10): 1745-52.

[23] Jaber RM, Mafrachi B, Al-Ani A, Shkara M. Awareness and perception of COVID-19 among the general population: A Middle Eastern survey. PLoS ONE [Internet]. 4 April 2021; 16: 1-10.

[24] Cuan-Baltazar JY, Muñoz-Perez MJ, Robledo-Vega C, Pérez-Zepeda MF, Soto-Vega E. Misinformation of COVID-19 on the internet: Infodemiology study. JMIR Public Health and Surveillance. 2020; 6(2): 1-9.

[25] Park JH, Moon JH, Kim HJ, Kong MH, Oh YH. Sedentary Lifestyle: Overview of Updated Evidence of Potential Health Risks. Korean Journal of Family Medicine. 2020; 41(6): 365-73.

[26] Yussif NM. Vitamin C. In: Vitamin C - an Update on Current Uses and Functions. 2018; 1-28. 